\title{
Intuition in the Design Studio: A Perspective on Student's Creativity and Design Process
}

\author{
Zeynep Ozge Yalcin \\ MSc Candidate, Izmir Institute of Technology, Faculty of Architecture, Department of Architecture, Izmir, Turkey
}

Received: February 25th 2021, Revised: June 3rd 2021, Accepted: June 12th 2021.

Refer: Yalcin, Z. O., (2021), Intuition in the Design Studio: A Perspective on Student's Creativity and Design Process, Journal of Design Studio, V.3, N.1, pp 37-48,

Z.O. Yalcin ORCID: 0000-0001-9165-8999

DOI: 10.46474/jds.886400 https://doi.org/10.46474/jds.886400

\begin{abstract}
In the twentieth century, as a result of the transition to a scientific approach in design, intuition lost its validity and design became a rational act. In well-defined problems, the design process could be structured with this scientific approach, however, in an ill-defined structure, rationality needs to be combined with intuition to analyzing the design problems, decisions making and generate solutions by supporting the creativity of design students. In this respect, intuition can assist to strengthen and develop the required abilities during the process. Accordingly, the aim is to understand the role of intuition, how students use it to work creatively through sketches, and conceptual ideas, and the problematic process of transformation into architectural knowledge in the design process. The study carried out a literature review to draw an understanding of the dimensions of intuition and its role in the architectural design studio. The results of the study demonstrate that intuition has a crucial role in the design process. Relatedly, the lack of intuition becomes problematic, due to the non-conveyable character that it cannot find a place for itself in the design education in terms of crits from tutors, and alteration of intuition into concrete representations leads to a gap between intuition and the final project. Furthermore, these problems could be eliminated through the coherent use of two features which are rational approach and intuition. In this respect, intuition, creativity, and rationality is needed to perform together in order to achieve success by deciphering the potentials of the project through the process.
\end{abstract}

Keywords: Intuition, creativity, design studio, designing process.

\section{Introduction}

Until the beginning of the twentieth century, design education followed intuitionism, and intuition was seen as one of the most widely accepted way to design (Orbey \& Erdogdu, 2020). Later, with the industrialized production techniques, there was a transition to a new perspective. This perspective is a scientific design process that includes the transition from scientific knowledge-based, "pre-industrial, craft-oriented design to a modern and industrialized design, using a mix of intuitive and non-intuitive design methods" (Cross, 2001, p. 52). Within this shift, intuition lost its validity to the logical positivism from which rational thought arose. In this notion, design became a rational act itself (Cross, 2001). However, intuition, as a supporter of the analytical mind, can involve in the design process and reclaim its validity and place. While the design is defined as a process, openended and ambiguous question, and problemsolving discipline (Goel, 1995) a design studio contains creativity, rational thinking, and practical problem-solving (Robinson, 2001). When it comes to problem-solving, a general design education should be justified in terms of "helping to develop students, able to understand the nature of ill-defined problems, how to tackle them, and how they differ from other kinds of 


\section{Journal of \\ Design Studio}

v:3 n:1 July 2021

problems" (Cross, 1982, p. 225). Once the problem is defined, students draw on both the research and their experiential base, applying abstract thinking and imagination through brainstorming to generate a variety of possible solutions. In the brainstorming stage, intuition may lead the way for students and creativity can be thought of like a burst of development (Dorst \& Cross, 2001).

In an ill-structured design problem, intuitive consciousness can operate with higher accuracy than conscious reasoning (Frank, O'Reilly \& Curran, 2006; Klein, 1998), in terms of strengthening and developing the abilities required to analyze ill-defined design problems and generate solutions. A better understanding of intuition will be an important contribution to understanding the design problem, decision making, and support students' creativity. This study re-asserts the importance of intuition in a design process to support students' creativity and problem-solving. The aim is to understand the role of intuition, how students use it to work creatively, and the problematic process of transforming it into architectural knowledge in the design process. This study sets out a review of the literature regarding the dimensions of intuition and its role in the architectural design studio. In the scope of this paper, how students use their intuition in the design process in the sketches, and conceptual idea stage, for creative problem-solving and the lack of turning intuition into architectural knowledge in the design process will be discussed.

Dane et al., (2012) argue that intuition has both positive and negative consequences. On the one hand, it is helpful when a person has a wealth knowledge of specific to the field. On the other hand, it will lead to negative consequences if the person has only low domain expertise. Accordingly, the role of intuition has changing effect regarding the level of expertise in the working area that a productive intuition only possible by doing more design activities. With balanced usage, intuition may help students for a creative design solution, the choice of knowledge, determining the problems, choosing one of the different alternatives produced, reaching the solution. In contrast, intuition in the design process may bring some new problems that there are some difficulties in providing rational explanations about turning intuition into architectural knowledge. Sketches and conceptual ideas can be defined as representation modes of intuition and contain creativity but when the idea becomes an architectural project the logical requirements are needed.

The lack of using intuition emerges when students try to formulate their intuitive and creative sketches, and conceptual ideas into a project that engages with the critics from instructors, architectural knowledge, technical requirements of an architectural problem, and representation of the project. This leads to a gap between students' intuitive design concepts and the final project. As an output of the project, the final design may not appear intuitively. The intuitive and creative lack, and the gap between students' intuitive design; sketches and conceptual ideas, and the final project still exist in the design process. Suh and Cho (2018) found that while intuitive students demonstrate more creative aspects at the beginning of the design phase, it is observed at the end for more analytical and adaptive students. So, this lack can only be completed with a new design process. This paper suggests a middle ground for a design studio, containing both rational and intuitive, that can be followed to support every stage of the process. In this respect, a project can be successful both technically and conceptually. Accordingly, it may support intuitive rational solutions by emphasizing the design process.

\section{Intuition}

Intuition may help students in the design process to use creativity as architectural knowledge, develop an understanding of illstructured design problems, produce alternatives, and reaching the solution. So, what is intuition?

There are many ideas about intuition presented by psychologists, philosophers, and other scholars. Psychological literature examines intuition as an implicit, form of knowledge. It is accepted as a short, instantaneous, and rapid 


\section{Journal of \\ Design Studio}

v:3 n:1 July 2021

process of knowing at least unconscious information structures (Bastick, 2003; Polanyi, 1966). In psychology, Daniel Kahneman (2011) defines intuition as an is an integral part of thinking. Due to the nature of the human brain, every person is intuitive, whether the person is aware or not (Laughlin, 1997). Every person uses intuition in their daily lives constantly. In addition, people's decision-making processes are often based on these intuitive unconscious processes such as associations, habits, memories, and emotions (Glöckner \& Witteman, 2010). It is generally regarded as a sudden, flash-like, instantaneous form of knowledge and a solution that provides insight into a problem that enters consciousness in a seemingly unbidden way (Bastick, 2003). For Henri Bergson (1946), the body is the core of perceptions, and intuition is the process of capturing one's self. In this process of selfsympathy, individuals catch themselves from within, and self-sympathy transforms into others in a heterogeneous way (Bergson, 1946). "To ask whether the universe exists only in our thought, or outside of our thought, is to put the problem in terms that are insoluble, even if we suppose them to be intelligible" (Bergson, 1991, p. 25). Raami (2015, p. 58), argues that Bergson's perspective as "intuition is fundamentally unrepresentative, it places us either above or below representations."

"Pure intuition, external or internal, is that of an undivided continuity. We break up this continuity into elements laid side by side, which correspond in one case to distinct words, in the other to independent objects. But just because we have thus broken the unity of our original intuition, we feel obliged to establish between the severed term a bond which can only then be external and superadded" (Bergson, 1991, p. 183).

In addition to Bergson, phenomenological philosopher Maurice Merleau-Ponty (1962) also mentions the role of the body as the center of perception. While Bergson states that the reality of things cannot be constructed or reconstructed Merleau-Ponty claims that perception is a subjective synthesis and experience is reconstructed (Bergson, 1991;
Merleau-Ponty, 1962; Raami, 2015). In social sciences, intuition is defined in connection with tacit knowledge by Polanyi (1966). Knowing here shows that "we can know more than we can tell" (Polanyi, 1966, p. 4). According to Polanyi (1966), even the knowledge itself is based on a tacit dimension. He also states that people are often unaware that they have tacit knowledge or may be valuable to others. Even if they are aware, tacit knowledge is difficult to be expressed it in writing and verbally. Polanyi (1966) describes intuition as awareness that illuminates the gap between tacit knowledge and focused knowledge. While focused knowledge is explained as explicit knowledge, defining what the person is dealing with, tacit knowledge described as the basic part of processing data (Polanyi, 1966). Tacit knowledge is the visible part of an expert's knowledge, know-how. Tacit knowledge and intuition are important in decision making, problem-solving. They can allow recognizing a problem and create a solution. As an example, many decision-makers mentioned having "an immense instinctive feel", " a high quality of understanding", and "an intuitive sense of the business" (Eisenhardt, 1999). From Faculty of Arts and Education, Tony Bastick (2003) defines intuition as (1) contrast with abstract reasoning, logic, or analytic thought, (2) sense of relations, (3) recentering, (4) influenced by experience, (5) emotional involvement.

Donald Officer (2005, p. 7) defines a summary of the sources of intuition as "(1) Intuitive knowledge may be self-explanatory, but not accessible or verifiable by an external reference. (2) Intuition is thought of as a tool that links creativity to practical results. (3) Intuition is synonymous with tacit knowledge: the essential but unexpressed knowledge needed to execute intricate tasks or skills. (4) Intuition may be associated with magic, the paranormal or the unconscious depending upon one's understanding of knowledge and reality."

According to Nuray Sungur (1992) the situations where intuitive methods are most useful are as follows (1) when there is a high level of uncertainty, (2) when there are very few clues about the situation, (3) when data are not 


\section{Journal of \\ Design Studio}

v:3 n:1 July 2021

sufficient for scientific predictions, (4) when previous facts about the problem are limited, (5) when the data start to decrease and new indicators start to emerge, (6) when numerous solution proposals arise, each with strong bases, (7) when it is necessary to make the right decisions in a short time.

\section{The Link between Intuition and Creativity} Henri Bergson (1946) believed that the most accurate form of knowing can only be achieved by intuitive actions, as he believed that the intuitive state had a direct connection with reality itself. Bergson (1946, p. 32) describes the state of creative consciousness as "immediate consciousness, a vision which is scarcely distinguishable from the object seen, a knowledge which is in contact and even coincidence", it is consciousness extended. For Bergson (1946), intuition is a function of the human mind that grasps the interpenetration of experience through this immediate consciousness.

The role of intuition is accepted in various fields. In the field of psychology, Boden (1994) says that the role of the mind's unconscious ability is profound in all creative processes, and intuition is seen by Bastick (2003) as the first and necessary stage of creativity. In the research in art and science, Weston Agor (1989) argued that intuition plays an important role in the creation and development of new ideas. In studies on innovations and problem solving, Root-Bernstein and Root-Bernstein (2003), emphasize that the act of creating comes from intuition. Paula Thomson (2006, p. 217) argued that "people who score high on intuition in psychological tests also tend to score high on creativity and divergent thinking." Many designers have also emphasized the importance of intuition in the creation process. (Mäkelä \& Numkulrat, 2011; Seitamaa-Hakkarainen et al., 2013). Intuition can be seen as a meaningful part of the creative design process. According to Durling, Cross and Johnson (1996, p. 6), 'Designers' creativity seems inextricably bound up with their particular personality types. Intuition seems to be at the core of the designers' special brand of creativity."
4.The role of Intuition in the Design Process

Design is generally defined as a process, openended and ambiguous question, and problemsolving discipline (Goel, 1995). The design process is considered one of the most challenging cognitive tasks as it requires the multidimensional use of cognitive skills. The design process is infinite, each problem is a symptom of another problem, and each solution often leads to a new problem. It is difficult to know which components a problem is related to and what information will be useful for a solution (Lawson, 1997). In the literature, the type of the design problem is defined as illdefined (Archer, 1979), ill-structured (Simon, 1973), or wicked (Rittel \& Webber, 1973). Friedman (2003, p. 508) states that most design definitions have three features in common "(1) design is a process, (2) this process is goaloriented, and (3) the purpose of design is solving problems, meeting needs, improving situations, or creating something new or useful." Due to its open-ended and ambiguous structure, there is no true, certain or single approach, methodology, result, or formula to follow for defining and solving these problems. A design process can change depending on the conditions of the studio environment, student, and design parameters. Design problems are full of uncertainties. This ambiguous nature of the design problem allows richness and creative solutions; they typically include conflicting assumptions and information that may lead to different solutions (Reiter-Palmon et al., 1997). Therefore, it is possible to define each design process as 'unique'. Non-routine design problems cannot be completely solved by routine problem-solving processes, different and potentially creative ideas and unpredictable solutions need to be generated (Rittel \& Webber, 1984). While well-defined problems can easily be solved with the help of systematic approaches, ill-defined problems can be solved by thinking in a designerly way.

Intuition, intertwined with tacit knowledge, experiences, memories, and implicit thoughts, seen as the apprenticeship in learning how to think in designerly ways that produce the deep insights which designers characteristically manifest (Durling, 1999). In a design problem, 


\section{Journal of \\ Design Studio}

v:3 n:1 July 2021

architects tend to focus on the solution and adjust the creation of their own (Lawson, 1997). A solution cannot be considered without its subject of the design, the design and the designer cannot be considered isolated of their emotions and intuitions. Architects base their choices or decisions on experiences and intuitions (Hogarth, 2001; Pedigo, 2005). Once the problem is defined, students draw on both the research and their individual experiential base, applying abstract thinking and imagination through brainstorming to generate a variety of possible solutions. In the brainstorming stage, intuition may lead the way for students and creativity can be thought of like a burst of development (Dorst \& Cross, 2001). In an ill-structured design problem, the analytical mind may overwhelm with too many options and fail to reach a solution when there is a lack of information or cannot imagine options beyond imagination. Intuition can assist to strengthen and develop the abilities required to analyze ill-defined design problems and generate non-routine solutions. As Shapiro and Spence (1997) note, intuition often bears a more important role than analysis to have a comprehensive perspective through a complex system's structure.

Dane and Pratt (2007, p. 45) claim that "intuition, as a holistically associative process, may help to integrate the disparate elements of an ill-defined problem into a coherent perception of how to proceed." Intuition may infuse throughout the process, which starts with defining the goals and objectives of the challenge and designing a plan to structure, enable individuals to develop an understanding of ill-structured design problems and, direct problem-solving. Design can be a skill created by the person using their full capacity. Besides the analytical mind and explicit knowledge, intuition intertwined with experiences, memories, tacit knowledge, and implicit thought could also be an important part of the design. As "we can know more than we can tell" (Polanyi, 1966, p. 4), we can also design more than we can learn. In designing a project there is an experience of having the idea and knowing it is right. Mehran Kheirollahi (2012, p. 58) stated that "many designers express the attempt to determine the process of designing as a struggle to recognize an inner sense whose result is not generally defined or recommended."

While MacKinnon (1962) defines designers as "intuitive", Durling, Cross, and Johnson (1996, p. 1) mentioned that "designers' strategies for problem-solving are different from many other professionals, and an intuitive way of working is preferred strongly." Krik Hamilton (2019) mentions that architects often come to design decisions based on their intuition and personal experience. As an example, designer Ken Yeang states "I trust the gut feeling, the intuitive hand, the intuitive feel about the project ... you can technically solve accommodation problems, you can solve problems of view and so on but which problem to solve first is a gut feeling . . . you can't explain it, but you feel that's right and nine times out of ten you are right" (Lawson, 2005, p. 203). Moreover, the psychological studies held in Royal Designers for Industry demonstrate that intuition has importance while deciding the right idea (Csordas, 1994). Durling et al., (1996, p. 5) also show that "over three quarters of representative design students have a preference for intuition (79\%) and a majority also prefer perception." Linzey (2001) states that architects, like scientists, are trained to be intuitive; they are encouraged to develop penetrating powers of observation, to see relations between things that other people are inclined to overlook. These studies were remarkable observations linking architects to intuition.

The experiences of designers show that intuition is an important tool of creative design solutions to ill-structured and complex problems. Pedigo (2005, p. 16) stated that "one goal of education should be to teach when people should use specific forms of deliberate thought." In a design process, students begin with sketches, conceptual ideas and take a path towards the final project. Robin Hogarth (2001) identifies the skills demonstrated by intuitively as (1) Contrast with abstract reasoning, logic, or analytic thought, (2) ability to accept and learn from emotions (3) desire to speculate and consider alternatives, (4) constant testing of 


\section{Journal of \\ Design Studio}

v:3 n:1 July 2021

perceptions, emotions, and speculation. And these skills are used in architecture such as sketches, 2D, and 3D visualization, sensitivity to experience, approach design tasks with alternative solutions.

\section{a. Sketches in the Design Process}

Mike Linzey (2001) states that architects' intuition is engaged in the act of drawing. Chris van Uffelen (2013, fourth cover) notes that "despite the nearly unending possibilities of computer-based methods, drawings and sketches remain the most intuitive expression method of architects." According to Uffelen (2013, description), "beyond the pure conveying of information through a mechanical drawing, the various techniques of manual drawing can convey individual sentiments and impressions." Architectural drawings that an architect makes in the process of designing are the records of relations between components and the stages of an evolving design (Linzey, 2001). Goel (1995) describes sketches as the tools used for creative alterations in design. In the design process, the role of sketches is described as the "primary nucleus" by Arnheim (1993, p. 16). Tate (2007, p. 71) mentions that the creative process "...consists of cyclical loops of feeling, responding, evaluating, selecting and communicating." Sketches have great importance in such a process because, during sketching, emotions and intuitions create some images in students' minds, and they can respond to certain design situations using them. Students can communicate about the design subject with the help of sketches. Sketches are self-communication tools that make designers' inner world much clearer and understandable even for them. This self-communication is defined by Goldschmidt (1991, p. 123) as "dialectics of sketching" and by Smith (2005, p. 2) as "personal dialogue." This dialogue has the potential to lead students to a new emotion, a new design idea according to their intuitions.

Unwin (2007, p. 105) remarks that "For Le Corbusier, sketching was a personal way gradually understanding more and more what he could do with architecture." From these points of view, it is clear that sketches play a very important role as a creative problem- solving tool in design studios. (Ledewitz, 1985). At the beginning of a design process, sketches are generally tentative, generic, and vague, as a positive quality. As Goel (1995, p. 193) points out, "ambiguity is important because one does not want to crystallize ideas too early and freeze design development." This vagueness helps designers to realize new opportunities (Arnheim, 1993). In this respect, the ambiguity of the sketches helps students to see new opportunities, brings positive developments, transformations, and acts according to their intuitions. In a design studio, students also use sketches as their graphic vocabulary, which play an important role in design thinking and affect how they understand and solve problems. It enables students to represent the design concept by drawing symbols and abstract forms and shows the functional and spatial relationships intuitively. Goldschmidt (1994) draws attention to how the act of sketching externalizes thought and leads to new ideas in his work on sketching. It helps him to create an image in his mind through making and perception. The resulting image can lead to the development of a conceptual design idea.

\section{b. Conceptual Idea in the Design Process}

Within the framework of conceptualization, sketches are defined as effective tools for containing intuition and creativity in design studios. Sketches lead the way to students, in project development, analysis, and find a conceptual idea. Linzey (2001) defines conceptual thinking as a kind of intuition in which the intuited object is an idea. They emerge as a visible image of the design process. It allows students to present potential ideas and solutions during the design process, along with recording new ideas and evaluating the design ideas (Soliman, 2017). When analyzing a design process, it can be seen that the initial stage of the process could be the key point in terms of the formation of the conceptual idea. According to Önal and Turgut (2017, p. 184), "the conceptual design process consists of creativity, which is a cognitive and social process that involves the generation of new ideas or concepts and new associations between existing ideas or concepts." The conceptual idea 


\section{Journal of \\ Design Studio}

v:3 n:1 July 2021

is the initial step of the design process where the design idea externalizes by abstract representations. In the conceptual design phase, sketches help students enter into formal and functional reasoning to visualize the spatial arrangements of forms and provide alternatives to solve the design problem. This phase is implemented through a variety of strategies, using diagrams, charts, graphs, interviews, surveys, and experiments to evaluate the design idea. They help students to transform their intuitions and the meaning of verbal expressions and turn them into a graphic context that helps solve design problems (Do \& Gross, 2001). It is argued by Do and Gross (2001) that, sketches and conceptual ideas are not only confined to provide convenience in resolving a problem but also play a central role as "the designer's principal means of thinking" (Herbert 1993), along with interacting with the drawings. Sketches and conceptual ideas in a design studio can be defined as an abstract representation of intuition. They are the act of design, where emotion, creativity, and intuition are embodied with representation. Due to the fact that conceptual ideas and sketches are ambiguous and open to diverse interpretations, they may consider as the most creative phase of the design. When analyzing the whole design process from beginning to end, it can be seen that the initial stage of the process could be the key point in terms of the formation of the conceptual idea creatively according to students' intuition but transforming that conceptual idea into an architectural language, to a final project contains some problems.

\section{The Lack of Using Intuition in the Design Process and Outcomes}

In literature, some people define intuition as the only way to create a unique design, while others are skeptical about the usefulness of intuition. Some scholars define intuition as an aspect of decision-making and believe it will lead the designer to be more critical about their work (Badke-Schaub \& Eris, 2014), on the contrary, others argued that intuition can be a dangerous tool for novice designers who lack experience (Badke-Schaub \& Eris, 2014; Goldschmidt 2014). In a similar way, Dane et al., (2012) state that intuition is helpful when the person possesses a rich body of domain-specific knowledge; however, intuition will lead to negative results in case the person has got only low domain expertise. Patricia Benner (2001) explains that "intuition and associated highlevel performance come after deep immersion in the field, extensive experience, and is reflective of mastery." Therefore, productive intuition should be considered as a tool of the experienced master designer rather than the novice. Successful use of intuition in the design process is possible by doing more and more design activities. With successful usage, intuition may help students for a creative design solution, the choice of knowledge, determining the problems, choosing one of the different alternatives produced, reaching the solution.

In contrast, intuition in the design process brings with it some problems. The design studio is defined as a complex teaching environment in terms of, "inherent conditions of inexpressibility", "vague purposes", and "the ambiguity of implicit theories." (Schön, 1981) Similar to the structure of these three, intuition: the unconscious, implicit, non-linguistic levels of the mind; sketches: tentative, generic, and vague; and conceptual ideas: abstract representations. In the design environment, this ambiguity, the difference between implicit and explicit messages, may lead to a misunderstanding between students, their intuitions, and instructors. In the early stages of design, students need feedback to enhance themselves, solve the design problem, and make sure they are on the right track. Instructors are involved throughout the whole process by providing crits to improve the students' work (Oh et al., 2013; Utaberta et al., 2010; 2013). In between critics, students try to integrate their conceptual ideas, sketches, and all their data into a single concrete final project, along with the critiques they receive from their instructors. This stage may define as one of the biggest challenges of the design process for students.

As Badke-Schaub and Eris (2014, p. 367) mentioned, "intuition can lead to decisions but does not the designer how to implement them." It may become difficult for students to implement their conceptual ideas into a physical 


\section{Journal of \\ Design Studio}

v:3 n:1 July 2021

model. Because of the implicit structure of the design studio, it is difficult to analyze the data and reflect the conceptual idea according to both their intuition and critics from instructors into the project in a comprehensible way. In the design process, there are some difficulties in providing rational explanations about turning intuition into architectural knowledge. During this phase, architectural representation of an idea, intuition, tacit and abstract knowledge should transform into concrete and tangible knowledge with the use of physical models, technical drawings, and renders. Sketches and conceptual ideas consist of intuition and creativity but when the idea should become an architectural project the logical requirement occurs. In this respect, the logical requirement that arises for the concretization of the design idea may begin to hamper the creative potential of intuition. In this phase, with the inclusion of drawings, programs, diagrams, site plans, plans, elevations, sections, details (Hurst, 2000) students concretize their sketches and conceptual ideas to set an architectural language. The lack of using intuition emerges when students try to formulate their intuitive and creative sketches and conceptual ideas into a project that engages with the critics from instructors, architectural knowledge, technical requirements of an architectural problem, and representation of the project.

As a result of that lack, when students could not translate their conceptual ideas into their design phase intuitively, they could leave and forget their ideas and start a completely different process focused on a mass design and instructors' critics without applying previous conceptual design ideas. They can focus on a project based on a concrete mass design ruled by critics. Instructors, implicitly, may impose their attitudes about design (Ledewitz, 1985). Most of the students may choose to modify their designs to follow the instructors' feedback instead of intuitions. They focus on examples given by the instructors or projects that instructors like. Being close to the instructors' perspective or personal aesthetic preferences may make students feel safe. However, projects liked by teachers begin to attract attention and this could turn out to be detrimental to the studio. The student's main argument may become success rather than design. Here, students limit their discussion to design within the instructors' critics, architectural and technical information. In that stage, the crystallization of ideas or freeze design development can be seen in the design studio. This allows concerns to dominate creativity, intuitive design, and the richness of the studio. Ledewitz (1985) states that any students' final presentations are disappointing because the physical form consequences of their design intentions have not been explored. This leads to a gap between students' intuitive design concepts and the final project. "A highly attuned sense of intuition in design does not necessarily lead to intuitive design outcomes" (Faste, 2017, p. 3). As a final project, the final design may not appear intuitively.

The intuitional and creative lack, and the gap between students' intuitive design; sketches and conceptual ideas, and the final project still exist in the design process. This might indicate that some designers are more aware of the role intuition plays in conceptual design thinking (Badke-Schaub \& Eris, 2014). This lack can only be completed with a new design process. Suh and Cho (2018) found that while intuitive students demonstrate more creative aspects at the beginning of the design phase, it is observed at the end for more analytical and adaptive students. Just as there is no true, certain, or single result or a formula to follow in design, there is also no certain way to design learning. In the design studio, a middle approach, containing both rational and intuitional, can be followed to support every stage of the process.

\section{Conclusion}

In this study, the importance of intuition and the lack of its usage in the design process are discussed. Intuition has been defined as an important aspect of decision-making in a variety of domains. This paper focused on the role of intuition in the design studio and argued that the implementation of intuition as a final project is a problematic aspect because the tendency to rational design process causes a strong decrease in the use of intuition in the design process. However, intuition strengthens 


\section{Journal of \\ Design Studio}

v:3 n:1 July 2021

creativity in stages of design as a design problem, problem-solving, decision making by expanding the awareness for any potentiality. However, in order to make it visible, it is needed to be transformed into a concrete presentation, which is the main problem faced by architectural students. Although this difficulty could be overcome with more experience, as a student who is at the beginning of the design discipline, the transformation of intuition into architectural knowledge is an area that requires more attention and work. Accordingly, while students deal with the problems executed in the crits or technical requirements of an architectural problem, easily leave their intuitive aspects. Although, they try to focus on it, especially at the conceptual idea through sketches, the lack of intuition is observed.

Intuition should be used throughout the entire design process and become supportive of analytical thinking. In this respect, a design can be successful both technically and conceptually. The more knowledge and skills students acquire, the more they will be able to use their intuition to guide them through the process. "Knowledge comes not from an assimilation of external information, but wholly from an internal dialogue between the individual and his inner self" (Balfour, 1981, p. 797). In conclusion, design education needs to support students in evaluating the pros and cons of using intuition in the design process. This study suggests a new design process, a middle ground, including many possible relations and meanings that can be defined by intuition and rationality. Accordingly, it may support intuitive rational solutions by an emphasis on observing design projects as a process that seeks an appropriate balance between intuition and rationality. Intuition, creativity, and rationality must all work together by completing each other and creating the strongest potential for the success of the project.

\section{Acknowledgments:}

I would like to express my gratitude to Prof. Dr. Fehmi Doğan for providing guidance throughout this paper.

\section{References:}

Agor, W, H. (1989). Intuition in organizations: leading and managing productively. Newbury Park: Sage Publications.

Archer, B. (1979). Design as a discipline. Design studies, 1(1), 17-20.

Arnheim, R. (1993). "Sketching and the Psychology of Design", Design Issues, Vol. 9, No. 2, Autumn, pp. 15-19.

Badke-Schaub, P. \& Eris, O. (2014). A theoretical approach to intuition in design: Does design methodology need to account for unconscious processes? In A. Chakrabarti \& L. Blessing (Eds.), An anthology of theories and models of design (pp. 353-370). London: Springer.

Balfour, A. (1981). Captive of Love and Ignorance: Architecture, Education and Practice. Architecture Education Study, 1, pp. 771-801.

Bastick, T. (2003). Intuition: Evaluating the construct and its impact on creative thinking. Stoneman \& Lang.

Benner, P. (2001). From novice to expert: Excellence and power in clinical nursing practice. Upper Saddle River, NJ: Prentice Hall.

Bergson, H. (1946). The Creative Mind: An introduction to metaphysics. Mineola, N.Y: Dover Publications.

Bergson, H. (1991). Matter and Memory. New York: Zone Books.

Boden, M. (1994). Dimensions of Creativity. Cambridge, MA: The MIT Press.

Cross, N. G. (1982). Designerly Ways of Knowing. Design Studies Vol. 3 No. 4. pp. 221227

Cross, N. (2001). Designerly Ways of Knowing: Design Discipline versus Design Science. Design Issues, 17(3), 49-55. 
v:3 n:1 July 2021

Csordas, T. (1994). Embodiment and Experience, Cambridge University Press, Cambridge, UK.

Dane, E. and Pratt, M. G. (2007). Exploring Intuition and Its Role in Managerial DecisionMaking. Academy of Management Review, Vol. 32, No. 1, pp. 33-54.

Dane, E., Rockmann, K. W., Pratt, M. G., (2012). When should I trust my gut? Linking domain expertise to intuitive decision-making effectiveness. Organizational Behavior and Human Decision Processes, 119(2), pp. 187194.

Do, E.Y. \& Gross, M.D. (2001). Thinking with diagrams in architectural design. In: Artificial Intelligence Review, 15: 135-149. Kluwer Academic Publishers, Netherlands, pp. 135136.

Dorst, K. \& Cross. N. (2001). Creativity in the design process: co-evolution of problemsolution. Design Studies. Volume 22, Issue 5, September, pp. 425-437

Durling, D. (1999). Intuition in Design. In Bulletin of 4th Asian Design Conference International Symposium on Design Science 1999, Nagaoka, Japan, October. ISBN 49980776-0-0 C3072.

Durling, D. Cross, N. \& Johnson, J. (1996). Personality and Learning Preferences of Students in Design-Related Disciplines IDATER 1996 Conference, Loughborough: Loughborough University. pp.1-6.

Eisenhardt, K. M. (1999). Strategy as Strategic Decision Making, MIT Sloan Management Review, Vol. 40, No. 3

Faste, H. (2017) Intuition in Design: Reflections on the Iterative Aesthetics of Form, CHI Conference.

Frank, M. J., O’Reilly, R. C., \& Curran, T. (2006). When memory fails, intuition reigns: midazolam enhances implicit inference in humans. Psychological Science: A Journal of the American Psychological Society / APS, 17(8), pp. 700-707.

Friedman, K. (2003). Theory Construction in Design Research: Criteria, Approaches, and Methods. Design Studies, Vol. 24, Issue 6, pp. 507-522, ISSN 0142-694X.

Glöckner, A., \& Witteman, C. (2010). Foundations for tracing intuition: Models, findings, categorizations in A. Glöckner \& C. Witteman (Eds.), Foundations for tracing intuition: Challenges and methods. Hove, East Sussex, New York, NY: Psychology Press \& Routledge, pp. 1-23.

Goel, V. (1995). Sketches of Thought, MIT Press, Cambridge, Massachusetts.

Goldschmidt, G. (1991). The Dialectics of Sketching, Creativity Research Journal, Vol. 4, No. 2, pp. 123- 143

Goldschmidt, G. (1994). On Visual Design Thinking: The vis kids of architecture, Design Studies, Vol. 15, No. 2, April, pp. 158-179.

Goldschmidt, G. (2014). Linkography unfolding the design process. Cambridge, Massachusetts: MIT Press.

Hatchuel, A. (2002). Towards design theory and expandable rationality: The unfinished program of Herbert Simon. Journal of Management and Governance, 5, 3-4.

Guilford, J. P. (1957). "A Revised Structure of Intellect", Report of the Psychological Laboratory, University of Southern California, No. 9.

Hamilton, K. (2019). Evidence, Intuition, and Experiment: Partners in the Design Process. Health Environments Research \& Design Journal 2019, Vol. 12(3) 66-71.

Herbert, D. M. (1993). Architectural Study Drawings. New York: Van Nostrand Reinhold. 


\section{Journal of \\ Design Studio}

v:3 n:1 July 2021

Hogarth, R. M. (2001). Educating Intuition, The University of Chicago Press, Chicago, Illinois, USA.

Hurst, F. (2000). Architectural Participatory Design Methods, The Graduate School, University of Wisconsin-Stout, A Research Paper Submitted in Partial Fulfillment of the Requirements.

Kahneman, D. (2011) Thinking, fast and slow (1st ed.) New York: Farrar, Straus and Giroux pp. 3-22.

Kheirollahi, M. (2012). The Place and Influence of Intuition in the Creativity of the Architecture Designing Process. International Journal of Architecture and Urban Development Vol.1, No.3.

Klein, G. A. (1998). Sources of power: How people make decisions Cambridge, Mass: MIT Press.

Laughlin, C. (1997). The Nature of Intuition: A Neurophysiological Approach in R. DavisFloyd \& P. S. Arvidson (Eds.), Intuition: The Inside Story: Interdisciplinary Perspectives New York: Routledge, pp. 19-37.

Lawson, B. (1997). How designers think: the design process demystified (3rd ed.) Oxford, Boston: Architectural Press.

Lawson, B. (2005). How designers think: the design process demystified (4th ed.) Oxford, Boston: Architectural Press.

Ledewitz, S. (1985). Models of Design in Studio Teaching, Journal of Architectural Education, Vol.38, No:2, pp. 2-8.

Linzey, M. (2001). On the Secondness of Architectural Intuition, Journal of Architectural Education (1984-) Sep. Vol. 55, No. 1 pp. 4350

MacKinnon, D. W. (1962). The Personality Correlates of Creativity: A Study of American Architects, In Nielson, G.S. (ed.) Proceedings of the Fourteenth Congress on Applied
Psychology, 2, Munksgaard, Copenhagen, Denmark. Pp. 11-39.

Mäkelä, M., \& Numkulrat, N. (2011). Making Design Matter in I. Koskinen, T. Härkäsalmi, R. Mazé, B. Matthews, \& J. J. Lee (Eds.), Practiseled Design Research, Nordes, pp. 120-128.

Merleau-Ponty, M. (1962). Phenomenology of perception New York: Humanities Press

Officer, D. R. (2005). The Unexplored Relationship Between Intuition and Innovation, The Innovation Journal: The Public Sector Innovation Journal. Volume 10(3), Article 10.

Oh, Y. Ishizaki, S. Gross, M. \& Do, E. (2013). A theoretical framework of design critiquing in architecture studios. Design Studies, 34, pp. 302-325.

Orbey, B. \& Erdogdu, G. P. S. (2020). Design process re-visited in the first-year design studio: between intuition and reasoning. International Journal of Technology and Design Education https://doi.org/10.1007/s10798-020-09573-2

Önal, G.K. Turgut, H. (2017). Cultural schema and design activity in an architectural design studio. Front. Archit. Res. 6, pp. 183-203.

Pedigo, S. (2005). Educating Intuition by Robin M. Hogarth, Book Summary the IntuitiveConnections Network.

Polanyi, M. (1966). The tacit dimension (1st ed.) Garden City, N.Y: Doubleday

Raami, A. (2015). Intuition Unleashed. On the application and development of intuition in the creative process. Aalto University Publication Series, Doctoral Dissertations. http://urn.fi/URN:ISBN:978-952-60-6108-5

Reiter-Palmon, R. Mumford, M. D. O'Connor, J. B. \& Runco, M. A. (1997). Problem Construction and Creativity: The Role of Ability, Cue Consistency, and Active Processing. Creativity Research Journal 10(1):9-23 


\section{Journal of \\ Design Studio}

v:3 n:1 July 2021

Rittel, H. W. \& Webber, M. M. (1973). Dilemmas in a general theory of planning. Policy Sciences, 4(2), 155-169.

Rittel, H. W. \& Webber, M. M. (1984). Planning Problems Are Wicked Problems. In Developments in Design Methodology; Cross, N., Ed.; John Wiley \& Sons: New York, NY, USA, pp. 135-144.

Robinson, K. (2001). Out of our minds: Learning to be creative. Oxford: Wiley.

Root-Bernstein, M. \& Root-Bernstein, R. (2003) Intuitive tools for innovative thinking in L.V. Shavinina (Ed.), International handbook on innovation,1st ed., Amsterdam: Elsevier Science, pp. 113-114.

Schön. D. A. (1981). Learning a Language, Learning to Design, Architecture Education Study Vol.1. pp. 339-471.

Seitamaa-Hakkarainen, P. Laamanen, T.K. Viitala, J. \& Mäkelä, M. (2013). Materiality and Emotions in Making. Techne Series: Research in Sloyd Education and Craft Science A, 20(3) Retrieved from https://journals.hioa.no/index.php/techneA/arti cle/view/702

Simon, H. A. (1973). The structure of illstructured problems. Artificial intelligence, 4(34), 181-201.

Shapiro, S., \& Spence, M. T. (1997). Managerial intuition: A conceptual and operational framework. Business Horizons, 40(1), pp. 63-68.

Smith, K. S. (2005). Architects' Drawings, Elsevier, Oxford. pp. 2.

Soliman, A. M. (2017). Appropriate teaching and learning strategies for the architectural design process in pedagogic design studios. Front. Archit. Res. 6, pp. 204-217.

Suh, J. \& Cho, J.Y. (2018). Analyzing Individual Differences in Creative Performance: A Case Study on the
Combinational Ideation Method in the Interior Design Process. J. Inter. Des, 43, 9-23

Sungur, N. (1992). Yaratici Dusunce. (Creative Thinking) Ozgur Yayin Dagitim, Istanbul

Tate, K. D. (2007). Art Bound: The Lived Experience of Creativity, University of Southern California, unpublished Ed.D. Dissertation. pp. 71.

Thomson, P. (2006). Are the Muses Real? Intuitive Inspiration, Possession and Dissociation, in Fisher, J. (ed.), Technologies of Intuition, YYZ Books, Toronto.

Uffelen, V. C. (2013). The Book of Drawings \& Sketches: Architecture, BRAUN, fourth cover.

Unwin, S. (2007). Analyzing Architecture Through Drawing, Building Research \& Information, Vol. 35, No.1, pp. 101-110.

Utaberta, N. Hassanpour, B. \& Zaharim, A. (2010). Redefining Critique Session as an Assessment Tool in Architecture Design Studio Class. WSEAS Transactions on Advances in Engineering Education. ISSN: 1790-1979 287 Issue 9, Vol. 7, pp. 287-298.

Utaberta, N. Hassanpour, B. Bahar, M.A. \& Che Ani, A.I. (2013). A Comprehensive Learning of Architecture Education: Understanding Critique Session as Learning Process and Criteria-based Assessment in the Architecture Design Studio, Procedia - Social and Behavioral Sciences, Vol. 102, ISSN 18770428, ISSN 1877-0428, https://doi.org/10.1016/j.sbspro.2013.10.709 pp. 21-32. 